\title{
Das
}

\section{flache Lelomdach}

und der

\section{elastische Theerfirniss}

\author{
nebst
}

einer chemischen Analyse

des

Steinkohlentheers.

Von

Dr. F. F. Runge,

ausserord. Prof. an der Universität zu Breslau,

z. $Z$, in Oranienburg.

Berlin, 1837.

Verlag der S a nder'schen Buchhandlung.

(C. W. Eichhoff.) 
